\title{
Measuring the ratio of femoral vein diameter to femoral artery diameter by ultrasound to estimate volume status
}

Zhihang Ma, Jiaxin Gai, Yinghan Sun, Yunpeng Bai, Hongyi Cai, Lei Wu, Lixiu Sun, Junyan Liu, Li Xue and Bingchen Liu*

\begin{abstract}
Background: Currently, the accepted effective method for assessing blood volume status, such as measuring central venous pressure (CVP) and mean pulmonary artery pressure (mPAP), is invasive. The purpose of this study was to explore the feasibility and validity of the ratio of the femoral vein diameter (FVD) to the femoral artery diameter (FAD) for predicting CVP and mPAP and to calculate the cut-off value for the FVD/FAD ratio to help judge a patient's fluid volume status.
\end{abstract}

Methods: In this study, 130 patients were divided into two groups: in group A, the FVD, FAD, and CVP were measured, and in group $B$, the FVD, FAD, and mPAP were measured. We measured the FVD and FAD by ultrasound. We monitored CVP by a central venous catheter and mPAP by a Swan-Ganz floating catheter. Pearson correlation coefficients were calculated. The best cut-off value for the FVD/FAD ratio for predicting CVP and mPAP was obtained according to the receiver operating characteristic $(R O C)$ curve.

Results: The FVD/FAD ratio was strongly correlated with CVP $(R=0.87, P<0.0000)$ and mPAP $(R=0.73, P<0.0000)$. According to the ROC curve, an FVD/FAD ratio $\geq 1.495$ had the best test characteristics to predict a $C V P \geq 12 \mathrm{cmH}_{2} \mathrm{O}$, and an FVD/FAD ratio $\leq 1.467$ had the best test characteristics to predict a $C V P \leq 10 \mathrm{cmH}_{2} \mathrm{O}$. An FVD/FAD ratio $\geq 2.03$ had the best test characteristics to predict an $\mathrm{mPAP} \geq 25 \mathrm{mmHg}$. According to the simple linear regression curve of the FVD/FAD ratio and CVP, when the predicted CVP $\leq 5 \mathrm{cmH}_{2} \mathrm{O}$, the FVD/FAD ratio was $\leq 0.854$.

Conclusion: In this study, the measurement of the FVD/FAD ratio obtained via ultrasound was strongly correlated with CVP and mPAP, providing a non-invasive method for quickly and reliably assessing blood volume status and providing good clinical support.

Keywords: Femoral vein diameter, Femoral artery diameter, CVP, mPAP, Volume status, Pulmonary hypertension

\section{Background}

In humans, blood volume is an important factor affecting the stability of haemodynamics, and an imbalance in blood volume can lead to a variety of critical clinical conditions. On the one hand, excess volume can

*Correspondence: liubingchen111@126.com Department of Cardiology, The Fourth Affiliated Hospital of Harbin Medical University, Harbin, Heilongjiang, China lead to oedema, ascites, and an increase in extracellular volume. On the other hand, insufficient volume can cause multiple organ dysfunction syndrome (MODS). Therefore, assessing volume status is critical for treating disease. Blood volume status can be assessed invasively or non-invasively. There are many invasive assessment methods, such as the measurement of central venous pressure (CVP) and mean pulmonary artery pressure (mPAP). CVP is influenced by a number of 
factors (including thoracic, pericardial, and abdominal pressures and the specification of operational measurements) [1]. As an indicator of fluid management, CVP sometimes cannot directly reflect blood volume and sometimes may mislead treatment decisions $[1,2]$. mPAP is an important index for evaluating pulmonary circulation volume status [3]. It is invasively measured with a pulmonary artery catheter (PAC), which needs to be monitored in an intensive care unit (ICU) and cannot provide fast and effective support for clinical work [4]. Moreover, there are certain risks associated with these invasive methods. Complications related to the use of a PAC include those associated with venipuncture, such as arteriovenous fistula, pneumothorax, and thrombosis; those associated with catheterization, such as arrhythmia; time-related complications of the PAC in the cardiovascular system, such as infection; and incorrect interpretation or use of exported data [4]. Given the above shortcomings of invasive assessment methods, a non-invasive, rapid, and effective method for assessing blood volume status is urgently needed.

Among the non-invasive evaluation methods that have been explored, measuring the inferior vena cava (IVC) diameter with ultrasound is considered a reliable evaluation method with a good correlation with volume status [5-8]. The IVC diameter and its collapsibility index (IVC-CI) can be measured by ultrasound to evaluate CVP $[9,10]$. However, the accuracy of measuring the IVC diameter via ultrasound is sometimes affected by certain factors, such as abdominal trauma, increased intraabdominal pressure, ventricular contraction, obesity, and the patient's body position during measurement $[5,11]$. Furthermore, measuring the IVC diameter by ultrasound is not as easy to obtain as that for the superficial vein, and the requirements for surveyors and ultrasonic instruments are higher [6]. mPAP is an important indicator of haemodynamic monitoring and is of great significance for the diagnosis and treatment of some pulmonary diseases. Currently, most non-invasive assessments are performed by echocardiography, but most of them are based on the peak velocity of tricuspid regurgitation; for patients without tricuspid regurgitation, mPAP cannot be measured by this method $[12,13]$.

In recent years, scholars have explored another noninvasive method for evaluating CVP: measurement of the femoral vein diameter (FVD) by ultrasound [14, 15]. Although experiments have suggested that the FVD has a good correlation with CVP, individual FVDs vary greatly and are affected by age, sex, height, body mass index, and other factors [16]. Therefore, to avoid the influence of these factors, we adopted the FVD/femoral artery diameter (FAD) ratio in this study and explored its correlation with CVP and mPAP.

\section{Materials and methods Study design}

This prospective study was conducted in the intensive care unit of the Fourth Affiliated Hospital of Harbin Medical University in China. The study was approved by a hospital committee (ethical approval number: 2021-SCILLSC-10), and informed consent was obtained from the patient or authorized person. The inclusion criteria were as follows: patients over 18 years of age who required haemodynamic monitoring, for example, multiple organ failure, shock, heart failure, myocardial infarction, acute pulmonary oedema, acute pulmonary embolism, etc. The exclusion criteria were as follows: (a) patients with a right atrium or right ventricle tumour; (b) patients with severe stenosis of the pulmonary valve or tricuspid valve; (c) patients with serious malformation of the pulmonary artery; (d) patients with thrombocytopenia or other serious clotting disorders; (e) patients with a skin infection at the puncture site; (f) patients receiving mechanical ventilation; and (g) patients with lower extremity artery/vein thrombosis, significant lower extremity artery plaque, lower extremity artery occlusion, inferior vena cava filter implantation, lower extremity varicose veins, or aortic stenosis.

Two highly trained doctors separately performed puncture and ultrasound examinations to minimize operational errors. The doctors performing the ultrasound examination were unaware of the values of CVP and mPAP. The patient was in the supine position throughout the ultrasound examination and haemodynamic monitoring. We used an EPIQ7 ultrasound machine (Phillips, USA) to measure the FVD and FAD.

First of all, twenty normal subjects were randomly selected, and their FVD and FAD were measured to determine the baseline FVD/FAD ratio. Then, the 130 patients were divided into two groups: Group A included patients requiring central venous catheter placement in ICU, such as shock, right heart failure, long-term infusion or intravenous hypertrophic therapy, etc. Group B included patients requiring Swan-Ganz floating catheter implantation in ICU, such as pulmonary oedema, pulmonary hypertension, and left heart failure, etc. In group $A$, the FVD, FAD, and CVP were measured. In group $B$, the FVD, FAD, and mPAP were measured.

\section{Ultrasound measurement method}

An ultrasound probe was used to first find the bifurcation position of the femoral artery, and then the probe was retracted proximally. The visual field of the bifurcation disappeared until the probe entered the main branch of the femoral artery, and the femoral artery and vein could be observed simultaneously. Under normal conditions, pulsation is an indication of the femoral artery, 
and its companion is the femoral vein (Fig. 1). The mean FVD and FAD (3-5 diametral lines in different directions) were measured, and then the patient was asked to cough or perform Valsalva manoeuvres. Changes in the femoral vein were observed within half a minute, and the FVD was measured again (mainly used for FVD less than FAD). The FVD/FAD ratio and the FVD/FAD ratio after cough (exFVD/FAD) were obtained.

\section{Haemodynamic monitoring}

After placing the central venous catheter/Swan-Ganz floating catheter through the right internal jugular vein, the pressure sensor was connected at the opening of the central venous catheter/Swan-Ganz floating catheter and was linked to the monitor. The pressure sensor was placed on the level of the patient's axillary midline. After the sensor was zeroed successfully, the values of CVP and mPAP were recorded.

\section{Statistical analysis}

All the data were input and analysed with R 4.0.2 software. The results are expressed as the mean \pm standard deviation (SD). $P<0.05$ was considered statistically significant. Multiple linear regression was used to analyse the relationship between multiple independent variables and dependent variables. The Pearson correlation coefficient was used to analyse the relationship between the FVD/ FAD ratio and CVP/mPAP. Simple linear regression was used to analyse the variable dependence. The receiver operating characteristic (ROC) curve was used to find the cut-off value.

\section{Results}

The study included 130 patients. There were 32 males and 33 females in group A and 28 males and 37 females in group B. In group A, the mean age was $65.5 \pm 10.2$ years, the mean FVD/FAD ratio was $1.54 \pm 0.30$, and the mean CVP was $13.22 \pm 4.11$ $\mathrm{cmH}_{2} \mathrm{O}$, the mean exFVD/FAD ratio for patients with the $F V D / F A D$ ratio $\leq 1$ is $1.23 \pm 0.10$. In group $B$, the mean age was $67.3 \pm 10.3$ years, the mean FVD/ FAD ratio was $2.00 \pm 0.32$, and the mean mPAP was $25.63 \pm 4.96 \mathrm{mmHg}$. The mean FVD/FAD ratio of twenty normal subjects was $1.18 \pm 0.04$. The mean exFVD/FAD ratio of twenty normal subjects was $1.52 \pm 0.09$.

The FVD/FAD ratio, age and sex were independent variables, CVP and mPAP were taken as dependent variables, and multiple linear regression analysis was performed (Table 1). Analysis of variance (ANOVA) was conducted, and the results are shown in Table 2. Age and sex had no significant effect on CVP and mPAP $(P>0.05)$. The FVD/FAD ratio was an influential factor for CVP and mPAP $(P<0.05)$. Therefore, simple linear regression was carried out with the FVD/FAD ratio as the only independent variable and CVP and mPAP as the dependent variables.

Figure 2 shows the simple linear regression curve of the FVD/FAD ratio and CVP. Linear regression showed that the FVD/FAD ratio was correlated with CVP $(\mathrm{R}=0.87, P<0.0000)$. The following regression equation was obtained: $\mathrm{CVP}=11.9665 \times(\mathrm{FVD} / \mathrm{FAD})-5.2147(\mathrm{~F}$ : 197.4, $P<0.0000)$. The adjusted R-square was 0.7542 .


Fig. 1 The images of femoral artery and vein were measured by ultrasound 
Table 1 Multiple regression analysis

\begin{tabular}{|c|c|c|c|c|c|c|c|c|}
\hline & CVP & & & & mPAP & & & \\
\hline & $\begin{array}{l}\text { Unstandardized } \\
\text { Coefficient B }\end{array}$ & $t$ & $P$ & $95 \% \mathrm{Cl}$ & $\begin{array}{l}\text { Unstandardized } \\
\text { Coefficient B }\end{array}$ & $\mathrm{t}$ & $P$ & $95 \% \mathrm{Cl}$ \\
\hline Constant & -3.926 & -1.776 & 0.081 & $-8.346-0.494$ & 4.174 & 1.203 & 0.234 & $-2.766-11.115$ \\
\hline $\mathrm{FVD} / \mathrm{FAD}$ & 11.997 & 14.184 & $<0.00$ & 10.306-13.689 & 11.647 & 8.734 & $<0.00$ & $8.980-14.313$ \\
\hline Age & -0.027 & -1.081 & 0.284 & $0.076-0.023$ & -0.039 & -0.943 & 0.350 & $-0.121-0.043$ \\
\hline Gender & 0.816 & 1.631 & 0.108 & $-0.184-1.817$ & 1.304 & 1.563 & 0.123 & $-0.365-2.973$ \\
\hline
\end{tabular}

Table 2 ANOVA test

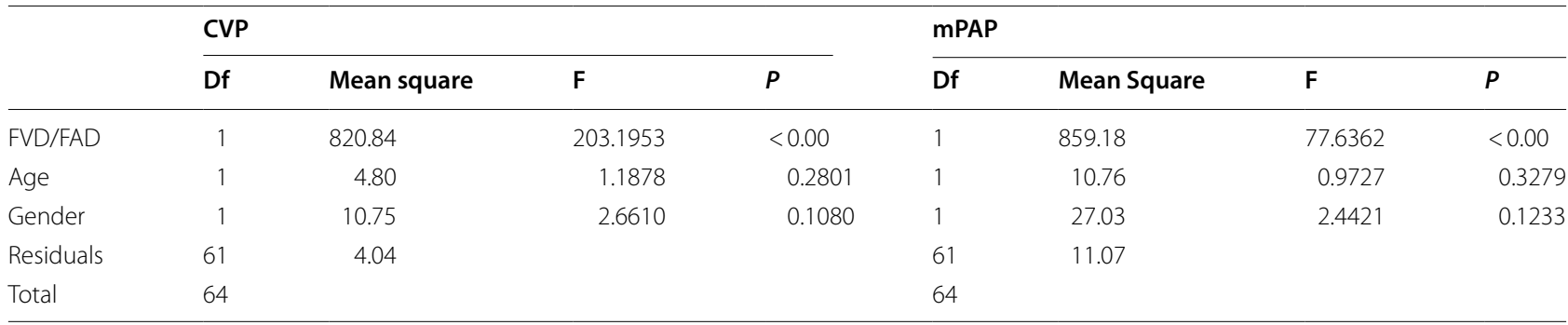

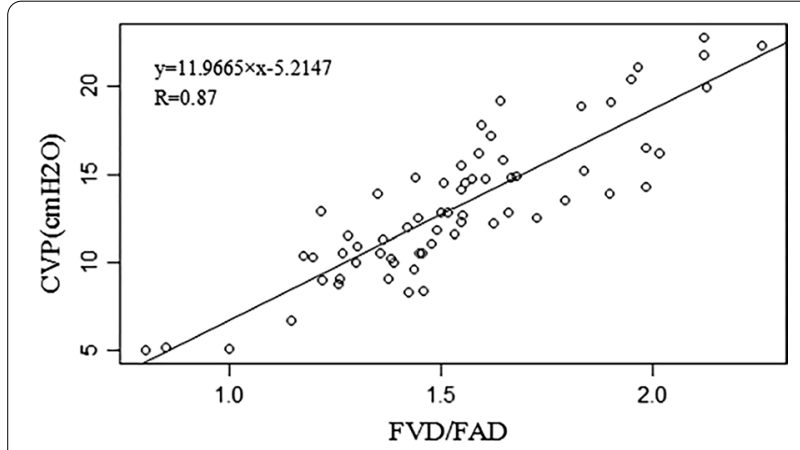

Fig. 2 Correlation between the FVD/FAD ratio and CVP. FVD femoral vein diameter, FAD femoral artery diameter, CVP central venous pressure

Figure 3 shows the simple linear regression curve of the FVD/FAD ratio and $\mathrm{mPAP}$. Linear regression showed that the FVD/FAD ratio was correlated with mPAP $(\mathrm{R}=0.73, P<0.0000)$. The following regression equation was obtained: $\mathrm{mPAP}=11.479 \times(\mathrm{FVD} / \mathrm{FAD})+2.643(\mathrm{~F}$ : 75.93, $P<0.0000$ ). The adjusted R-square was 0.5393 . However, when the FVD/FAD ratio was greater than 2.0, the adjusted R-square reached 0.6068 .

Figure 4 shows the area under the curve (AUC) of various CVP values predicted by the FVD/FAD ratio. For prediction of $\mathrm{CVP} \geq 12 \mathrm{~cm} \mathrm{H}_{2} \mathrm{O}$ by the $\mathrm{FVD} / \mathrm{FAD}$ ratio, the AUC was 0.945 (95\% CI, 0.891-0.998). The best FVD/ FAD ratio cut-off values were obtained according to the generated ROC curve. An FVD/FAD ratio $\geq 1.495$ had

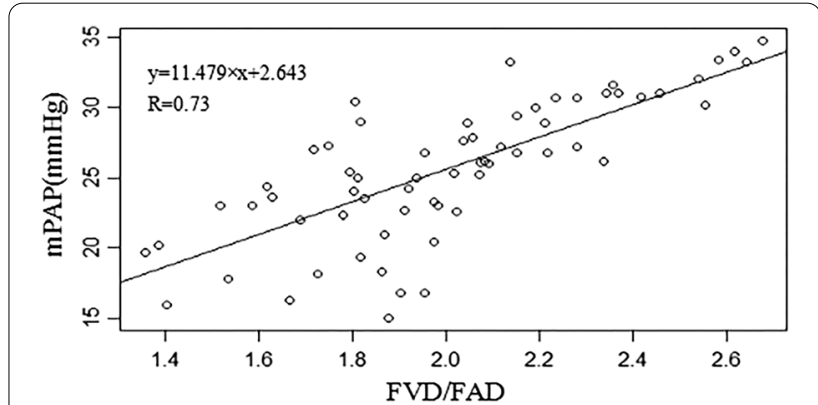

Fig. 3 Correlation between the FVD/FAD ratio and mPAP. FVD femoral vein diameter, FAD femoral artery diameter, mPAP mean pulmonary artery pressure

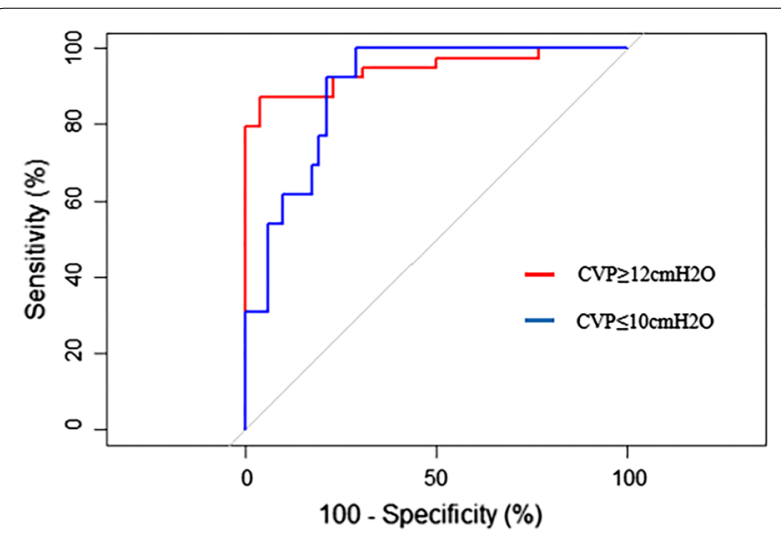

Fig. 4 Receiver operating characteristic curve for prediction of various CVP values by the FVD/FAD ratio 
the best test characteristics to predict a CVP $\geq 12 \mathrm{cmH}_{2} \mathrm{O}$ (sensitivity $87 \%$; specificity $96 \%$; positive predictive value 97\%; negative predictive value $83 \%$ ). For prediction of $\mathrm{CVP} \leq 10 \mathrm{cmH}_{2} \mathrm{O}$ by the FVD/FAD ratio, the AUC was 0.896 (95\% CI, 0.819-0.974). An FVD/FAD ratio $\leq 1.467$ had the best test characteristics to predict a CVP $\leq 10$ $\mathrm{cmH}_{2} \mathrm{O}$ (sensitivity $100 \%$; specificity $71 \%$; positive predictive value $46 \%$; negative predictive value $100 \%$ ). According to the simple linear regression curve of the FVD/FAD ratio and CVP, when the predicted $\mathrm{CVP} \leq 5 \mathrm{cmH}_{2} \mathrm{O}$, the $\mathrm{FVD} / \mathrm{FAD}$ ratio was $\leq 0.854$.

Figure 5 shows the AUC of the mPAP value predicted by the FVD/FAD ratio. For prediction of $\mathrm{mPAP} \geq 25 \mathrm{mmHg}$ by the FVD/FAD ratio, the AUC was 0.889 (95\% CI, 0.811-0.967). An FVD/FAD ratio $\geq 2.03$ had the best test characteristics to predict an mPAP $\geq 25 \mathrm{mmHg}$ (sensitivity $74 \%$; specificity $100 \%$; positive predictive value $100 \%$; negative predictive value $87 \%$ ).

\section{Discussion}

Several studies have reported the evaluation of CVP by ultrasound measurement of the IVC or internal jugular vein (IJV) [17-20]. In a study by Nik Muhamad NA et al., the IVC diameter at end expiration was better at predicting CVP than the IJV height [21]. In a study by Prekker ME et al., the maximal IVC diameter was better at predicting CVP than the IJV aspect ratio [6]. However, it is a challenge to perform high-quality IVC measurements via ultrasound due to factors such as abdominal gas, abdominal dressings, or poor acoustic windows [22, 23]. Other studies have estimated mPAP by measuring the velocity of pulmonary regurgitation at the beginning of diastole, but this is difficult to measure, and changes in the structure of the right ventricle make it more difficult to measure $[24,25]$.

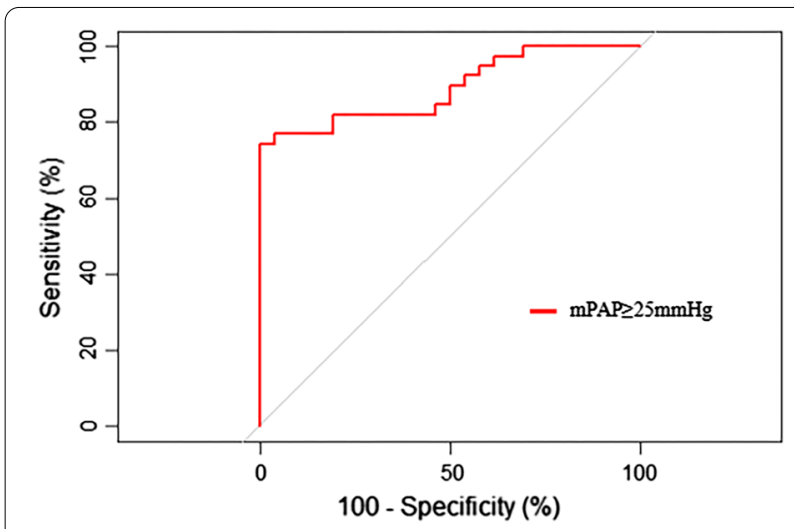

Fig. 5 Receiver operating characteristic curve for prediction of mPAP value by the FVD/FAD ratio
We performed baseline measurements in the normal population. Most of the blood in the normal human vascular system (approximately 65\%) is in the veins, and most of the blood that flows to the lower extremities via the femoral artery returns almost equally to the femoral vein. This was also confirmed by the close equivalence of FVD and FAD under ultrasound observation in normal subjects. Therefore, it can be inferred that if the FVD is significantly greater than the FAD, it can prove venous system volume overload; if the baseline FVD is slightly smaller than the FAD and FV fails to expand effectively after coughing, it can prove that the patient's blood volume is low. Therefore, volume status can be easily, quickly and accurately judged by accurate measurement of the FVD and FAD. Femoral artery and vein are mayor vessels, running close to the skin even in overweight personssuperficial vessels, easy to measure under ultrasound. However, in patients with venous insufficiency, the volume of the femoral vein increased significantly [26], so we excluded the patients with venous insufficiency in this study.

In this study, we studied another non-invasive method for volume status assessment: the FVD/FAD ratio. CVP and mPAP were predicted by the FVD/FAD ratio. According to the $\mathrm{R}$ values obtained from this experiment, the FVD/FAD ratio was strongly correlated with CVP $(\mathrm{R}=0.87)$ and mPAP $(\mathrm{R}=0.73)$. In the study by Ciozda $\mathrm{W}$ et al., the authors summarized the correlation between the IVC diameter and the IVC-CI measured by ultrasound and CVP or right atrial pressure (RAP) that had been published in recent years [5]. The correlation coefficient $\mathrm{R}$ values between the ultrasound measurements of the maximum IVC diameter and CVP or RAP ranged from 0.35 to 0.86 , with $57 \%$ having an $\mathrm{R}$ value between 0.5 and 0.78 . The correlation coefficient $\mathrm{R}$ values between ultrasound measurements of IVC-CI and CVP or RAP ranged from -0.27 to -0.76 , among which $62 \%$ were between -0.5 and -0.76 . The correlation coefficient $R$ between the FVD/FAD ratio measured by ultrasound and CVP in this experiment was 0.87 . The FVD/FAD ratio was slightly better than the IVC in the correlation with CVP. The FVD/FAD ratio in this study was used to evaluate not only venous indicators but also arterial indicators.

In the simple linear equation established between the FVD/FAD ratio and CVP, the adjusted R-square was 0.7542 , which means that $75.42 \%$ of the CVP variance was affected by the FVD/FAD ratio. In the simple linear equation of the FVD/FAD ratio and mPAP, the adjusted R-square was 0.5393 , which means that $53.93 \%$ of the variance in mPAP was due to the FVD/FAD ratio. When the FVD/FAD ratio was greater than 2.0, the adjusted R-square was 0.6068 , which means that $60.68 \%$ of the mPAP variance was due to the FVD/FAD ratio. In this 
study, we performed two sets of ROC analyses: (a) In this study, the best cut-off value of the FVD/FAD ratio for predicting a $\mathrm{CVP} \geq 12 \mathrm{cmH}_{2} \mathrm{O}$ was 1.495 . The best cutoff value of the $\mathrm{FVD} / \mathrm{FAD}$ ratio for predicting a CVP $\leq 10$ $\mathrm{cmH}_{2} \mathrm{O}$ was 1.467. In previous studies, $\mathrm{CVP} \leq 10 \mathrm{cmH}_{2} \mathrm{O}$ was selected as the node for ROC curve analysis [6, 14]. Although there was a small number of CVP $\leq 5$ $\mathrm{cmH}_{2} \mathrm{O}$ measurements, we determined that an FVD/ FAD ratio $\leq 0.854$ predicted a CVP $\leq 5 \mathrm{cmH}_{2} \mathrm{O}$ through the simple linear regression curve of the $\mathrm{FVD} / \mathrm{FAD}$ ratio and CVP. When FVD/FAD ratio $\leq 1$, the mean exFVD/ FAD ratio was $1.23 \pm 0.10$, which was far lower than the exFVD/FAD ratio of normal subjects. This suggests that the exFVD/FAD ratio is helpful for the diagnosis of hypovolemia. (b) In this study, the best cut-off value of the FVD/FAD ratio for predicting an $\mathrm{mPAP} \geq 25 \mathrm{mmHg}$ was 2.03 . The specificity and positive predictive value reached $100 \%$, indicating that when the $\mathrm{FVD} / \mathrm{FAD}$ ratio was $\geq 2.03$, all mPAP measurements according to the PAC were $\geq 25 \mathrm{mmHg}$. Although the FVD/FAD ratio in this study could not wholly and accurately predict mPAP, the FVD/FAD ratio could be a good screen for pulmonary hypertension.

There are some limitations in this study. First, we preferred high CVP groups in this study because some patients with hypovolemia were already receiving fluid therapy at the time of measurement. Therefore, there may be some deviations in the estimation and prediction of low CVP groups. Second, the sample size of our study was small, and the selected population was relatively homogeneous, so the results may not be representative of all populations. Therefore, we will increase the study of hypovolemic patients in the follow-up study to further verify the effectiveness of this method.

In conclusion, this study showed that the FVD/FAD ratio could accurately assess blood volume status and had certain clinical application value for diagnosing heart failure, assessing acute internal blood loss, diagnosing pulmonary hypertension, and so on.

\section{Conclusions}

In this study, the measurement of the FVD/FAD ratio obtained via ultrasound was strongly correlated with CVP and mPAP. There was a linear relationship between the FVD/FAD ratio and CVP or mPAP. The exFVD/FAD ratio is helpful for the diagnosis of hypovolemia. Moreover, the FVD/FAD has a screening effect on patients with high mPAP.

\footnotetext{
Abbreviations

CVP: Central venous pressure; mPAP: Mean pulmonary artery pressure; FVD: Femoral vein diameter; FAD: Femoral artery diameter; MODS: Multiple organ dysfunction syndrome; PAC: Pulmonary artery catheter; ICU: Intensive care
}

unit; IVC: Inferior vena cava; IVC-Cl: Inferior vena cava collapsibility index; ROC: Receiver operating characteristic; AUC: Area under the curve; IJV: Internal jugular vein; RAP: Right atrial pressure.

\section{Acknowledgements}

The authors thank the patients and their families for their participation and cooperation in this study.

\section{Authors' contributions}

$B C-L$ was responsible for the conception and design of the research and for providing technical guidance. $L-X$ was responsible for ultrasonic guidance and ultrasonic image collection. Zh-M wrote the first draft and added important intellectual content. JX-G, YH-S, and JY- $L$ contributed to data collection and analysis. YP-B, HY-C, and L-W were responsible for literature retrieval. LX-S modified the chart. Final draft read and approved by all authors.

\section{Funding}

This work was supported by a grant from the National Natural Science Foundation of China Project [Grant No. 81670381 awarded to Bingchen Liu]. The funders have no role in study design, data collection and analysis, manuscript preparation or publication decisions.

\section{Availability of data and materials}

The datasets used and analysed during the current study are available from the corresponding author on reasonable request.

\section{Declarations}

Ethics approval and consent to participate

Approval was obtained from the ethics committee of Harbin Medical University. The procedures used in this study adhere to the tenets of the Declaration of Helsinki. The written informed consent was obtained from all patients or authorized persons.

\section{Consent for publication}

Not applicable.

\section{Competing interests}

The authors declare that there is no conflict of interest in this manuscript.

Received: 7 May 2021 Accepted: 5 October 2021

Published online: 20 October 2021

\section{References}

1. De Backer $D$, Vincent $J$ L. Should we measure the central venous pressure to guide fluid management? Ten answers to 10 questions. Crit Care. 2018;22(1):43. https://doi.org/10.1186/s13054-018-1959-3.

2. Marik PE, Baram M, Vahid B. Does central venous pressure predict fluid responsiveness? A systematic review of the literature and the tale of seven mares. Chest. 2008;134(1):172-8. https://doi.org/10.1378/chest. 07-2331.

3. Task Force for Diagnosis and Treatment of Pulmonary Hypertension of European Society of Cardiology (ESC); European Respiratory Society (ERS); International Society of Heart and Lung Transplantation (ISHLT), Galiè N, Hoeper MM, Humbert M, Torbicki A, Vachiery JL, Barbera JA, Beghetti M, Corris P, Gaine S, Gibbs JS, Gomez-Sanchez MA, Jondeau G, Klepetko W, Opitz C, Peacock A, Rubin L, Zellweger M, Simonneau G. Guidelines for the diagnosis and treatment of pulmonary hypertension. Eur Respir J. 2009;34(6):1219-63. https://doi.org/10.1183/09031936.00139009

4. Evans DC, Doraiswamy VA, Prosciak MP, Silviera M, Seamon MJ, Rodriguez Funes V, Cipolla J, Wang CF, Kavuturu S, Torigian DA, Cook CH, Lindsey DE, Steinberg SM, Stawicki SP. Complications associated with pulmonary artery catheters: a comprehensive clinical review. Scand J Surg. 2009;98(4):199-208. https://doi.org/10.1177/145749690909800402.

5. Ciozda W, Kedan I, Kehl DW, Zimmer R, Khandwalla R, Kimchi A. The efficacy of sonographic measurement of inferior vena cava diameter as an estimate of central venous pressure. Cardiovasc Ultrasound. 2016;14(1):33. https://doi.org/10.1186/s12947-016-0076-1. 
6. Prekker ME, Scott NL, Hart D, Sprenkle MD, Leatherman JW. Point-of-care ultrasound to estimate central venous pressure: a comparison of three techniques. Crit Care Med. 2013;41(3):833-41. https://doi.org/10.1097/ CCM.0b013e31827466b7.

7. Sekiguchi H, Seaburg LA, Suzuki J, Astorne WJ, Patel AS, Keller AS, Gajic $\mathrm{O}$, Kashani KB. Central venous pressure and ultrasonographic measurement correlation and their associations with intradialytic adverse events in hospitalized patients: a prospective observational study. J Crit Care. 2018:44:168-74. https://doi.org/10.1016/j.jcrc.2017.10.039.

8. Zengin S, Al B, Genc S, Yildirim C, Ercan S, Dogan M, Altunbas G. Role of inferior vena cava and right ventricular diameter in assessment of volume status: a comparative study: ultrasound and hypovolemia. Am J Emerg Med. 2013;31(5):763-7. https://doi.org/10.1016/j.ajem.2012.10.013.

9. Stawicki SP, Braslow BM, Panebianco NL, Kirkpatrick JN, Gracias VH, Hayden GE, Dean AJ. Intensivist use of hand-carried ultrasonography to measure IVC collapsibility in estimating intravascular volume status: correlations with CVP. J Am Coll Surg. 2009;209(1):55-61. https://doi.org/10. 1016/j.jamcollsurg.2009.02.062.

10. Zanobetti M, Prota A, Coppa A, Giordano L, Bigiarini S, Nazerian P, Innocenti F, Conti A, Trausi F, Vanni S, Pepe G, Pini R. Can non-invasive ventilation modify central venous pressure? Comparison between invasive measurement and ultrasonographic evaluation. Intern Emerg Med. 2017;12(8):1279-85. https://doi.org/10.1007/s11739-016-1574-8.

11. Bano S, Qadeer A, Akhtar A, Ata Ur-Rehman HM, Munawar K, Hussain SW, Khan MT, Zafar R. Measurement of internal jugular vein and common carotid artery diameter ratio by ultrasound to estimate central venous pressure. Cureus. 2018;10(3):e2277. https://doi.org/10.7759/cureus.2277.

12. Kasai H, Matsumura A, Sugiura T, Shigeta A, Tanabe N, Yamamoto K, Miwa H, Ema R, Sakao S, Tatsumi K. Mean pulmonary artery pressure using echocardiography in chronic thromboembolic pulmonary hypertension. Circ J. 2016;80(5):1259-64. https://doi.org/10.1253/circ..CJ-15-1080.

13. Berger M, Haimowitz A, Van Tosh A, Berdoff RL, Goldberg E. Quantitative assessment of pulmonary hypertension in patients with tricuspid regurgitation using continuous wave Doppler ultrasound. J Am Coll Cardiol. 1985;6(2):359-65. https://doi.org/10.1016/s0735-1097(85)80172-8.

14. Cho RJ, Williams DR, Leatherman JW. Measurement of femoral vein diameter by ultrasound to estimate central venous pressure. Ann Am Thorac Soc. 2016;13(1):81-5. https://doi.org/10.1513/AnnalsATS.201506-337BC.

15. Malik A, Akhtar A, Saadat S, Mansoor S. Predicting central venous pressure by measuring femoral venous diameter using ultrasonography. Cureus. 2016;8(11):e893. https://doi.org/10.7759/cureus.893.

16. Fronek A, Criqui MH, Denenberg J, Langer RD. Common femoral vein dimensions and hemodynamics including Valsalva response as a function of sex, age, and ethnicity in a population study. J Vasc Surg. 2001;33(5):1050-6. https://doi.org/10.1067/mva.2001.113496.

17. Ilyas A, Ishtiaq W, Assad S, Ghazanfar H, Mansoor S, Haris M, Qadeer A, Akhtar A. Correlation of IVC diameter and collapsibility index with central venous pressure in the assessment of intravascular volume in critically ill patients. Cureus. 2017;9(2):e1025. https://doi.org/10.7759/cureus.1025.
18. Martin LD, Ziegelstein RC, Howell EE, Martire C, Hellmann DB, Hirsch GA. Hospitalists' ability to use hand-carried ultrasound for central venous pressure estimation after a brief training intervention: a pilot study. J Hosp Med. 2013;8(12):711-4. https://doi.org/10.1002/jhm.2103.

19. Huguet R, Fard D, d'Humieres T, Brault-Meslin O, Faivre L, Nahory L, Dubois-Randé JL, Ternacle J, Oliver L, Lim P. Three-dimensional inferior vena cava for assessing central venous pressure in patients with cardiogenic shock. J Am Soc Echocardiogr. 2018;31(9):1034-43. https://doi.org/ 10.1016/j.echo.2018.04.003.

20. Parenti N, Scalese M, Palazzi C, Agrusta F, Cahill J, Agnelli G. Role of internal jugular vein ultrasound measurements in the assessment of central venous pressure in spontaneously breathing patients: a systematic review. J Acute Med. 2019;9(2):39-48. https://doi.org/10.6705/j.jacme. 201906_9(2).0001.

21. Nik Muhamad NA, Safferi RS, Robertson CE. Internal jugular vein height and inferior vena cava diameter measurement using ultrasound to determine central venous pressure: a correlation study. Med J Malaysia. 2015;70(2):63-6.

22. Jassim HM, Naushad VA, Khatib MY, Chandra P, Abuhmaira MM, Koya SH, Ellitthy MSA. IJV collapsibility index vs IVC collapsibility index by point of care ultrasound for estimation of CVP: a comparative study with direct estimation of CVP. Open Access Emerg Med. 2019;11:65-75. https://doi. org/10.2147/OAEM.S176175.

23. Naghipour B, Faridaalaee G. Correlation between central venous pressure and inferior vena cava sonographic diameter; Determining the best anatomic location. Emerg (Tehran). 2016;4(2):83-7.

24. Kanda T, Fujita M, lida O, Masuda M, Okamoto S, Ishihara T, Nanto K, Shiraki T, Takahara M, Sakata Y, Uematsu M. Novel echocardiographic approach to the accurate measurement of pulmonary vascular resistance based on a theoretical formula in patients with left heart failurepilot study. Circ J. 2015;79(11):2408-13. https://doi.org/10.1253/circj. CJ-15-0575.

25. - Howard LS, Grapsa J, Dawson D, Bellamy M, Chambers JB, Masani ND, Nihoyannopoulos P, Simon R Gibbs J. Echocardiographic assessment of pulmonary hypertension: standard operating procedure. Eur Respir Rev. 2012;21(125):239-48. https://doi.org/10.1183/09059180.00003912. Erratum in: Eur Respir Rev. 2012 Dec 1;21(126):370. PMID: 22941889.

26. Kahle B, Hennies F, Hummel S, Petzoldt D. Quantitative venous severity scoring using the venous arterial flow index by duplex sonography. Dermatol Surg. 2002;28(10):937-41. https://doi.org/10.1046/j.1524-4725. 2002.02073.x.

\section{Publisher's Note}

Springer Nature remains neutral with regard to jurisdictional claims in published maps and institutional affiliations.

\footnotetext{
Ready to submit your research? Choose BMC and benefit from:

- fast, convenient online submission

- thorough peer review by experienced researchers in your field

- rapid publication on acceptance

- support for research data, including large and complex data types

- gold Open Access which fosters wider collaboration and increased citations

- maximum visibility for your research: over $100 \mathrm{M}$ website views per year
}

At BMC, research is always in progress.

Learn more biomedcentral.com/submissions 